\title{
Multidisciplinary research in Spain. A network perspective
}

\author{
Díaz-de la Fuente S, Ahedo V, Caro J , Pereda M, Santos JI , Galán JM \\ Recibido: 12 de Enero de 2021 \\ https://doi.org/10.37610/dyo.v0i74.601 \\ Aceptado: 05 de Marzo de 2021
}

\begin{abstract}
This contribution presents a network approach to analyse the current situation of multidisciplinary research in Spain. To this aim, all coordinated projects funded by the Spanish Ministry of Science and Innovation in the 2013-2018 timeframe have been considered as a proxy for multidisciplinarity. The information on each institution has been complemented with its geographical location (latitude, longitude and autonomous community) as well as with its position according to the Scimago Institutions Rankings. Two networks were built: the network of the interactions between institutions and the network of thematic areas. Topological analyses were conducted on the two. Our results show that the two networks have a clear modular structure, and the role detection analyses conducted on both networks provide relevant insights into the relative importance of the different research institutions and thematic areas respectively.
\end{abstract}

\section{Keywords}

Multidisciplinary research; network analysis; community structure; ANEP thematic areas

\footnotetext{
\ilvia Díaz-de la Fuente * sddelafuente@ubu.es

iD

https://orcid.org/0000-0002-5961-3368

Virginia Ahedo *

vahedo@ubu.es

iD https://orcid.org/0000-0002-9812-388X

Jorge Caro *

jcaro@ubu.es

iD https://orcid.org/0000-0002-5065-4841

María Pereda **

maria.pereda@upm.es

iD https://orcid.org/0000-0002-6151-1176

José Ignacio Santos *

jisantos@ubu.es

iD https://orcid.org/0000-0002-6653-043X

José Manuel Galán *

jmgalan@ubu.es

iD https://orcid.org/0000-0003-3360-7602

* Dept. Ingeniería de Organización. Escuela Politécnica

Superior. Universidad de Burgos. Avenida Cantabria S/N, 09006 Burgos, Spain

** Grupo de Investigación Ingeniería de Organización y

Logística (IOL), Departamento Ingeniería de Organización, Administración de empresas y Estadística, Escuela Técnica

Superior de Ingenieros Industriales, Universidad Politécnica de Madrid. C/ José Gutiérrez Abascal, 2. 28006, Madrid, Spain.

Unidad Mixta Interdisciplinar de Complejidad y Comportamiento Social (UMICCS), Spain.

Grupo Interdisciplinar de Sistemas Complejos (GISC),

Madrid, Spain.
}

\section{Introduction (Background)}

At present, we are witnessing some tension in the scientific context between excessive disciplinary specialisation on the one hand, and the complex nature of the reality to be studied on the other (Ramadier 2004; Fair 2010). Global challenges such as climate change, the emergence and spread of new epidemics, migrations and inequality -among othersdemand the involvement of all scientific, social, economic, ecological and ethical spheres in pursuit of solutions (Caro et al. 2020a). In the same vein, the attainment of the United Nations Sustainable Development Goals requires integrated approaches and effective interdisciplinary collaborations, as noted by Ramaswamy et al. (2020). Notably, the limitations of disciplinary research to address problems and goals of such magnitude are primarily scientific; most disciplinary studies focus on isolated issues instead of fully addressing phenomena, which translates into a fragmented comprehension of the problems under consideration. In order to understand systems completely, it would be necessary to analyse their entire set of components, as well as the dynamics between them (Doblaré Castellano \& Alarcón Álvarez 2008).

For such an endeavour, it becomes necessary: 1) to challenge real-world complexity by overcoming static ontological and epistemological frameworks; and 2) to transform highly fragmented and bureaucratic structures for knowledge generation through effective collaboration between professionals and the research community on the one hand, as well as with the rest of society on the other (Lawrence \& Després 2004). 
In an attempt to overcome the limitations of the traditional disciplinary framework, several supra-disciplinary research practices such as multidisciplinarity, interdisciplinarity and/or transdisciplinarity have emerged. These research approaches represent a continuum and differ by the degree of integration and collaboration between the disciplines they encompass, as well as by the reasons that drive such collaboration (Mobjörk 2010; Caro et al. 2020b). Nevertheless, several barriers stand in the way of those integrative approaches, being the most prominent ones governmental and institutional (underfunding, institutional organisation, decentralised budgeting models, discipline-based promotion and hiring structures) and cross-disciplinary specific (conflicting epistemic values, conceptual frameworks, different jargons, etc.) (Lazer et al. 2020; Brown, Murray, Furlong, Coco \& Dablander 2021).

Remarkably, at the governmental and scientific policy levels, several measures are being taken to overcome some of those obstacles, being particularly noteworthy the encouragement of a highly cross-disciplinary scientific approach in the 9th European Framework Programme Horizon Europe -the EU research and innovation framework programme for the period from 2021 to 2027 (Graf 2019).

In the present contribution, we intend to test the waters of multidisciplinary research in Spain so as to establish a baseline of the current situation. Until now, most of the studies devoted to measuring multidisciplinarity in scientific collaboration have been conducted through bibliometric studies of indexed publications (Xie, Li, Li, Duan \& Ouyang 2018; Zuo \& Zhao 2018), by focusing on particular institutions and analysing their collaborative patterns (Leone Sciabolazza, Vacca, Kennelly Okraku \& McCarty 2017), and/or by assessing through empirical evidence the productivity of multidisciplinary collaborative research versus individual research (Benson et al. 2016). In our work, however, we are deepening the line of research initiated in Díaz-de la Fuente et al. (2020), which adopts a network approach to shed light onto multidisciplinarity in Spain. In particular, we have significantly expanded the database to include both the Retos and Excelencia (in English Challenge and Excellence) project calls of the Spanish Ministry of Science and Innovation so as to avoid possible analysis biases, and we have applied some of the most leading-edge network analysis techniques, such as role detection and centralisation measures. In addition, we have analysed the correlation between multidisciplinary activity in Spanish academic institutions and some other institutional metrics.

\section{Research proposal}

In the present study we extend the previous work on multidisciplinary research in Spain by Díaz-de la Fuente et al. (2020) by complementing the dataset with the Excellence coordinated projects funded by the Spanish Ministry of
Science and Innovation from 2013 to 2018. All the analyses in this contribution have been conducted on both datasets together.

More precisely, we have built two different networks: (i) the network of research institutions, in which the institutions with a coordinated project constitute the nodes, and a link exists between them if they work in the same project; and (ii) the network of the interactions between the thematic areas of the ANEP (Agencia Nacional de Evaluación y Prospectiva, in English National Agency of Evaluation), in which the ANEP areas of knowledge are the nodes, and a link exists between them if they concur in the same coordinated project.

Through the analysis of these two networks, in the present contribution, we intend to answer the following research questions:

1 Which institutions lead multidisciplinary research in Spain and what role do they play in the network of institutions?

2 Does the relative position of the institution in the Scimago Institutions Rankings have an impact on the number of coordinated projects the institution is awarded?

3 Does interdisciplinary research in Spain respond to geographic patterns? This question will be addressed both at the individual and autonomous community level.

4 Which scientific fields gather the greatest number of coordinated projects?

5 What role do the different scientific areas play as interaction/connection elements in the networks of multidisciplinarity?

\section{Data and problem formalisation}

All the data were extracted from the documents containing the resolutions of the Challenge and Excellence calls for coordinated projects from the Spanish Ministry of Science and Innovation in the 2013-2018 timeframe.

In such documents, which were publicly accessible at the official website https://www.ciencia.gob.es/, the information available includes (among others): reference of the project, name of the project, recipient institution, recipient research centre, execution period, amount of money and classification per thematic area according to the ANEP. This information was completed by adding the following fields: Spanish autonomous community, Scimago Institutions Ranking (SIR) Overall, SIR Research, SIR Innovation and SIR Societal (Vargas Quesada, Bustos-González \& de Moya Anegón 2017). 
It should be noted that -unless otherwise specified-in this contribution we work at the institution level. As stated in the research proposal, we have built two different networks: a network of the relations between research institutions and the network of interactions between thematic areas. In the first network, the institutions constitute the nodes, and a link exists between them if they share a coordinated project. This network has been then transformed into a weighted network where the weight represents the number of coordinated projects that the two institutions have in common.

As for the second network, its nodes represent the twenty thematic areas of the ANEP classification, existing a link between them if both areas of knowledge are present in a given coordinated project. In a subsequent step, this second network was also transformed into a weighted network, where the weight of a link represents the number of projects in which the two research fields converged. It should be noted that the assignment of thematic areas to each institution was done semi-automatically, taking into account the name of the recipient centres.

The remaining of this paper is structured as follows: The Analyses \& Results section is divided into two welldifferentiated blocks: (i) the analysis of the network of institutions and (ii) the analysis of the network of the ANEP thematic areas. The first block addresses research questions 1 to 3 , while the second block deals with research questions 4 and 5. Throughout the two blocks, the fundamentals of the analysis techniques applied are succinctly described, and then the results obtained are presented and interpreted.

\section{Analyses \& Results}

\subsection{Analysis of the Network of Institutions}

Since in the work by Díaz-de la Fuente et al. (2020) on the Challenge coordinated projects the most relevant properties of the network of institutions were already obtained, in the present contribution we go one step further and conduct a role detection analysis in accordance with Guimerà et Amaral $(2005 \mathrm{a}, 2005 \mathrm{~b})$, and assess the possible relations between the relative position of the institutions in the SIR rankings and the number of projects they are granted.

To better understand the topology of complex networks, it is key to identify the role of the different nodes within the network. Therefore, we explored the network of institutions by means of the role detection methodology proposed by Guimerà and Amaral (2005a, 2005b). More specifically, their methodology is based on the connectivity of the nodes and consists of two steps: (i) the identification of the communities in the network, and (ii) the classification of the different nodes according to the set of system-independent "universal roles" they define.
Regarding the first step, even though Guimerà and Amaral propose a modularity-maximization community detection algorithm based on simulated annealing, in our contribution we have chosen the Louvain community detection algorithm (Blondel, Guillaume, Lambiotte \& Lefebvre 2008) because of its popularity, computational efficiency and the good results it has proven to provide in networks of a broad range of sizes (Lancichinetti \& Fortunato 2009). Notably, the Louvain algorithm is also aimed at the maximisation of the modularity of the network. In particular, it starts by assigning each node to its own community and continues by merging the communities that imply the highest increase in modularity (Newman \& Girvan 2004). Recall that the modularity coefficient (Q) quantifies the extent to which the network community structure differs from that which would have been formed if links were placed at random while preserving the degree of each node (see equation [1]). Intuitively, one can see that if the number of links between communities is significantly higher or lower than would be expected by chance, a phenomenon in the network should be creating this structure. The modularity coefficient is calculated as follows:

$$
Q=\frac{1}{2 m} \sum_{i j}\left(A_{i j}-\frac{k_{i} k_{j}}{2 m}\right) \delta\left(c_{i}, c_{j}\right)
$$

where $\mathrm{m}$ is the number of links in the network, $\mathrm{A}_{\mathrm{ij}}$ is the corresponding entry of the adjacency matrix, $\mathrm{k}_{\mathrm{i}}$ is the degree of the node $\mathrm{i}$, and $\delta\left(\mathrm{c}_{\mathrm{i}}, \mathrm{c}_{\mathrm{j}}\right)=1$ if the node $\mathrm{i}$ belongs to the same community as the node $\mathrm{j}$, and zero otherwise.

As for the second step, it deserves more detailed consideration. The idea behind the whole role detection methodology is that nodes with the same role should have similar topological properties. To formally assess those properties, two indices are defined: the within-module degree $\mathrm{z}$-score and the participation coefficient, which determine how the node is positioned in its own community and in relation to other communities, respectively.

The within-module degree $z$-score of a given node $i$ measures how intensely connected it is to other nodes in its own community. It is defined as follows:

$$
z_{i}=\frac{\kappa_{i}-\bar{\kappa}_{s_{i}}}{\sigma_{\kappa_{s_{i}}}}
$$

Where $\kappa_{\mathrm{i}}$ is the intra-community degree of node i, i.e., the number of links of node $i$ to other nodes in its own community $\mathrm{s}_{\mathrm{i}} ; \kappa_{\mathrm{si}}^{-}$is the average degree of community $\mathrm{s}_{-} \mathrm{i}$; and $\sigma_{\mathrm{Ksi}}$ is the standard deviation of the degree in community $\mathrm{s}_{\mathrm{i}}$. Therefore, the within-module degree $\mathrm{z}$-score determines if a node is strongly or poorly connected to other nodes in its community by comparing its intra-community connections with the average number of connections of the nodes in that community.

On its part, the participation coefficient of node $\mathrm{i}$ is defined as: 


$$
P_{i}=1-\sum_{s=1}^{N_{M}}\left(\frac{\kappa_{i s}}{\kappa_{i}}\right)^{2}
$$

Where $\kappa_{\text {is }}$ is the intra-community degree -the number of links of node $i$ to other nodes in its community- and $\kappa_{i}$ is the total degree of node $i$. Thus, the participation coefficient of a node is zero if all its links are within its own community, and close to one if its links are uniformly distributed among the different communities identified.

Guimerà et al. propose seven universal roles according to which the different nodes in a network can be classified. Notably, such definition of roles is done in relation to the values of the within-module degree z-score and the participation coefficient that each node may exhibit. More precisely, the different roles are divided into non-hubs $(\mathrm{z}<2.5)$ and hubs $(\mathrm{z} \geq 2.5)$, being the subdivisions of the nonhub nodes: R1- Ultra-peripheral nodes (nodes that have all their edges within their own community); R2 - Peripheral nodes (nodes with at least $60 \%$ of their links within their own community); R3 - Non-hub connectors (nodes with half of their edges within their community); and R4 - Nonhub kinless nodes (nodes with fewer than $35 \%$ of their links within their own community). As for the hub nodes, they are subdivided into: $\mathrm{R} 5$ - Provincial hubs (nodes with $\mathrm{z} \geq 2.5$ and at least $5 / 6$ of their links within their own module); R6 Connector hubs (nodes with $\mathrm{z} \geq 2.5$ and at least half of their links within their community); and R7 - Kinless hubs (nodes with $\mathrm{z} \geq 2.5$ and less than half of their links within their module).

In the network of institutions, the role detection analysis was conducted as follows: 100 iterations of the Louvain algorithm were run, and for each of the 100 partitions obtained, the corresponding values of the z-score within module degree and the participation coefficient were calculated for each institution (node). The average values of both metrics over those 100 runs, and the subsequent classification of all the institutions into roles are shown in Table 1 and Fig. 1.
Table 1 List of the institutions with more than 10 funded coordinated projects and their role according to the methodology by Guimerà and Amaral. Note that the institutions are arranged first by role and then in descending order of their degree value.

\begin{tabular}{|c|c|c|}
\hline Institution & Role & k \\
\hline Instituto de Astrofísica de Canarias (IAC) & $\mathrm{R} 2$ & 64 \\
\hline Universidad Politécnica de Cartagena & $\mathrm{R} 2$ & 55 \\
\hline Universidad de la Laguna & $\mathrm{R} 2$ & 42 \\
\hline Institut de Física D’altes Energies & $\mathrm{R} 2$ & 37 \\
\hline Universidad de Lleida & $\mathrm{R} 2$ & 37 \\
\hline Fundació Institut de Recerca En L'energia de Catalunya & $\mathrm{R} 2$ & 30 \\
\hline Fundació Institut Català de Nanociència I Nanotecnologia & $\mathrm{R} 2$ & 23 \\
\hline Universitat Ramon Llull, Fundació Privada & $\mathrm{R} 2$ & 22 \\
\hline Institut D’estudis Espacials de Catalunya & $\mathrm{R} 2$ & 21 \\
\hline Asoc Cic Nanogune & $\mathrm{R} 2$ & 17 \\
\hline Institut de Recerca I Tecnologia Agroalimentàries (IRTA) & $\mathrm{R} 2$ & 16 \\
\hline Fundació Institut Català de Recerca de L'aigua & $\mathrm{R} 2$ & 16 \\
\hline Fundación Imdea Nanociencia & $\mathrm{R} 2$ & 11 \\
\hline Universidad de Valencia & R3 & 175 \\
\hline Universitat Politècnica de València & R3 & 173 \\
\hline Universidad Autónoma de Madrid & $\mathrm{R} 3$ & 154 \\
\hline Universidad de Sevilla & R3 & 138 \\
\hline
\end{tabular}




\begin{tabular}{|c|c|c|}
\hline Universidad Carlos III de Madrid & $\mathrm{R} 3$ & 133 \\
\hline Universidad de Castilla la Mancha & R3 & 106 \\
\hline Universidad de Granada & R3 & 101 \\
\hline Universidad de Vigo & $\mathrm{R} 3$ & 100 \\
\hline Universidad de Málaga & $\mathrm{R} 3$ & 90 \\
\hline Centro de Investigación Energética Medioambiental Y Tecnológica (CIEMAT) & R3 & 82 \\
\hline Universidad de Valladolid & $\mathrm{R} 3$ & 81 \\
\hline Universidad de Cantabria & $\mathrm{R} 3$ & 81 \\
\hline Universidade de Santiago de Compostela & R3 & 80 \\
\hline Instituto Nacional de Técnica Aeroespacial Esteban Terradas (INTA) & R3 & 73 \\
\hline Universidad de Extremadura & $\mathrm{R} 3$ & 67 \\
\hline Universidad de Salamanca & $\mathrm{R} 3$ & 66 \\
\hline Universidad de Murcia & R3 & 64 \\
\hline Universitat de Girona & R3 & 62 \\
\hline Universidade da Coruña & $\mathrm{R} 3$ & 62 \\
\hline Universitat Jaume I de Castelló & $\mathrm{R} 3$ & 58 \\
\hline Universidad Rey Juan Carlos & R3 & 58 \\
\hline Universidad Pública de Navarra & $\mathrm{R} 3$ & 58 \\
\hline Universidad de Alcalá & R3 & 57 \\
\hline Universidad de Oviedo & $\mathrm{R} 3$ & 56 \\
\hline Universidad de Las Islas Baleares & R3 & 55 \\
\hline Universitat Rovira I Virgili & $\mathrm{R} 3$ & 47 \\
\hline Universidad de Alicante & $\mathrm{R} 3$ & 46 \\
\hline Universidad de Córdoba & $\mathrm{R} 3$ & 44 \\
\hline Universitat Pompeu Fabra Cct & $\mathrm{R} 3$ & 42 \\
\hline Universidad Miguel Hernández de Elche & R3 & 40 \\
\hline Universidad de Almería & $\mathrm{R} 3$ & 39 \\
\hline Universidad de Jaén & $\mathrm{R} 3$ & 38 \\
\hline Universidad de Las Palmas de Gran Canaria & R3 & 38 \\
\hline
\end{tabular}




\begin{tabular}{|c|c|c|}
\hline Universidad Pablo de Olavide de Sevilla & $\mathrm{R} 3$ & 34 \\
\hline Universidad Nacional de Educación a Distancia & R3 & 33 \\
\hline Universidad de Huelva & R3 & 32 \\
\hline Universidad de León & R3 & 32 \\
\hline Universidad de Cádiz & R3 & 31 \\
\hline Centro de Estudios a Investigaciones Técnicas & R3 & 22 \\
\hline Universidad de Navarra & $\mathrm{R} 3$ & 22 \\
\hline Universidad de la Rioja & R3 & 22 \\
\hline Instituto Español de Oceanografía (IEO) & R3 & 21 \\
\hline Instituto Nacional de Investigación Y Tecnología Agraria Y Alimentaria (INIA) & R3 & 20 \\
\hline Universidad de Burgos & $\mathrm{R} 3$ & 17 \\
\hline Instituto Geológico Y Minero de España (Igme) & R3 & 13 \\
\hline Consorci Per A la Construcció Equipament I Explotació del Laboratori de Llum de Sincroto & $\mathrm{R} 3$ & 13 \\
\hline Fundación Universitaria San Pablo CEU & R3 & 12 \\
\hline Agencia Estatal Consejo Superior de Investigaciones Científicas (CSIC) & R6 & 609 \\
\hline Universidad de Barcelona & R6 & 212 \\
\hline Universidad Politécnica de Madrid & R6 & 209 \\
\hline Universidad Complutense de Madrid & R6 & 191 \\
\hline Universidad Autónoma de Barcelona & R6 & 127 \\
\hline Universitat Politècnica de Catalunya & R7 & 191 \\
\hline Universidad del País Vasco Euskal Herriko Unibertsitatea & R7 & 155 \\
\hline Universidad de Zaragoza & R7 & 122 \\
\hline
\end{tabular}


Figure 1 Role analysis of the network of institutions built based on the coordinated projects they share. Recall that node size is proportional to the degree of the node

\section{Institutions' role}

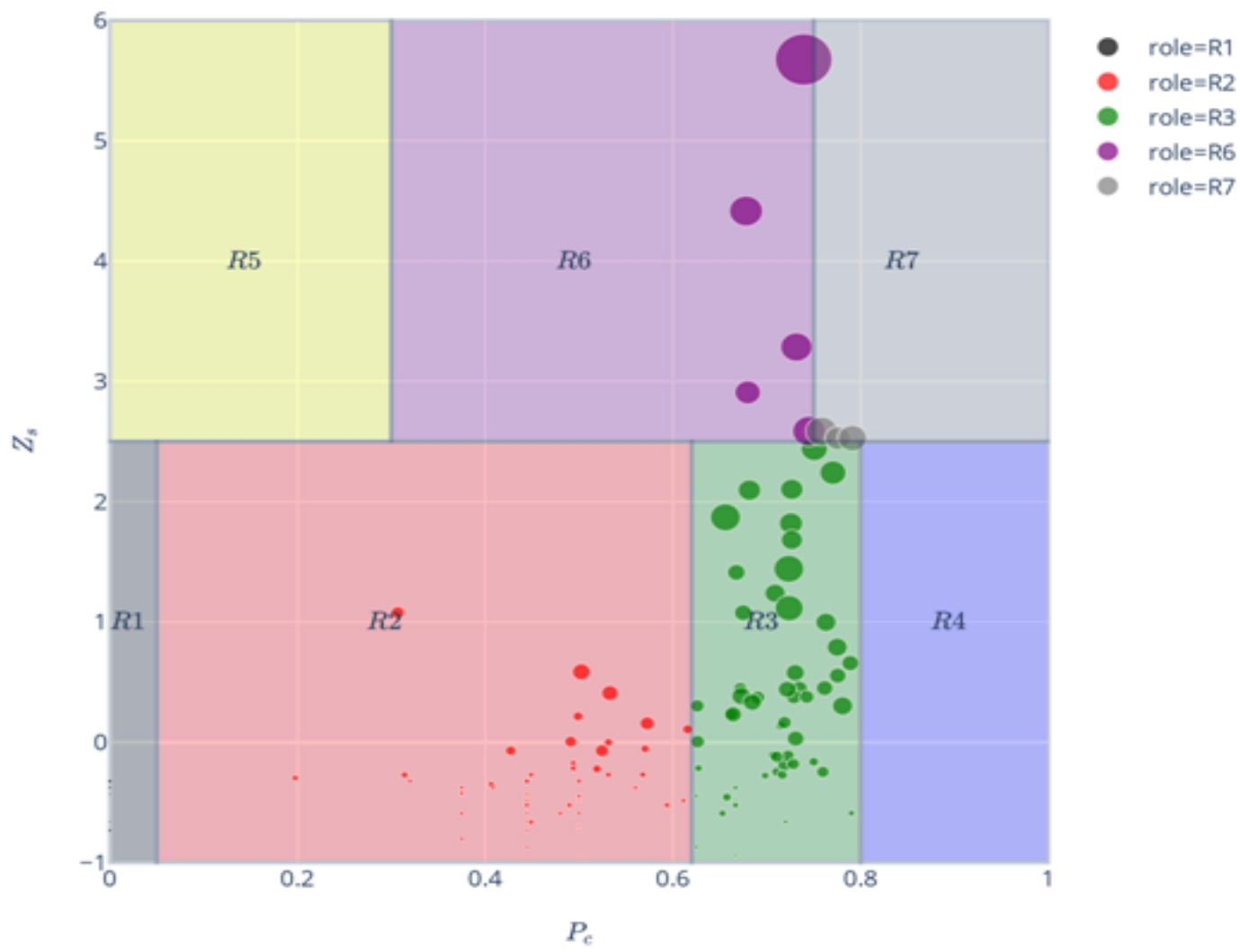

As it can be seen in both Table 1 and Fig. 1, Spanish institutions fall under roles R1 - ultra-peripheral nodes (23.1\%), R2 - peripheral nodes $(39.9 \%)$, R3 - non-hub connectors $(32.4 \%)$, R6 - connector hubs $(2.9 \%)$ and R7 - kinless hubs $(1.7 \%)$. In the context of multidisciplinarity, this makes perfect sense, as its inter-pretation would be that the subset of institutions falling under R1 are non-hubs -i.e., nodes that do not have a large number of links-whose circle of collaboration is limited exclusively to their own community; the group of R2 nodes (peripheral nodes) are non-hubs that collaborate mostly with members of their community but that do also have collaborators in other communities; the set of nodes falling under R3 are non-hubs as well, but in this case, playing an eminently connector role, that is, they link institutions from different communities (something which is to be expected in the context of multidisciplinary enterprises); the nodes in R6 (connector hubs) are the equivalent to R3 but in hub version, that is, they have a high number of links and connect different institutions outside their own communities; and nodes in R7 (kinless hubs) are hubs that are not very strongly related to any community in particular, not even the one they have been assigned to.

The second question that we address in this work in relation to research institutions is the identification of factors that are associated with and can partly explain the institutional characteristics that determine the intensification in multidisciplinary research and vice versa. To this end, we have resorted to the analysis of the position of the institutions in the different indicators of the Scimago Institutions Ranking, and of how these positions are related to participation in coordinated projects in the research calls under study.

The Scimago Institutions Ranking is a ranking that classifies research institutions according to different composite indicators. Specifically, it is composed of the weighting of three dimensions: research performance, innovation outputs, and so-cietal impact. The research index takes into account different indicators: excel-lence with leadership, normalized impact, output, scientific talent pool, scientific leadership, international collaboration, high-quality publications and excellence (and recently -fundamentally from 2019- some other metrics that are not included in our study since we have taken 2017 data as representative of the timeframe of our analysis). The innovation indicator is based on two indicators: innovative knowledge and the percentage of the scientific publication output cited in patents. Lastly, societal impact weights the number of incoming links to an institution's domain and the number of pages associated with the institution's URL according to Google (Vargas Quesada, Bustos-González \& de Moya Anegón 2017). These three indicators are weighted $50 \%, 30 \%$, and $20 \%$ to obtain a general measure of the institution's performance (overall ranking). 
To identify the associations of each pair of variables considered, we used two types of correlation: Pearson correlation coefficient and Spearman correlation coefficient. Pearson correlation indicates the level of linear association between two variables. It is bounded in the range -1 and 1 , with the sign indicating whether the association is positive or negative. Spearman correlation, also in the range -1 to 1 , focuses primarily on the association's direction, determining whether, as one variable increases, the other also increases or decreases, but not necessarily in a linear fashion.

The results of these analyses are provided in Fig. 2. Note that when no value is presented in the correlation matrices, it means that for a significance level of 0.05 , no statistically significant association was found between the two variables. Our results show a robust association by both Pearson and Spearman coefficients between the number of coordinated projects obtained by each institution and a prominent research ranking position (SIR Research). As a consequence of the foregoing, given that SIR Research represents 50\% of the SIR Overall indicator, there is also a high correlation between the number of coordinated projects ob-tained and the overall ranking (SIR Overall). In terms of innovation, there is also a significant relationship between the number of projects and the position in SIR Innovation, but of moderate intensity. In contrast, the trend in terms of social visibility does not appear to be linear, although there exists a certain pattern depending on the ranking position (see Spearman coefficient). From all the above, our results suggest that the relationships between the SIR indices and multidisciplinary research are not different -at least at this level of analysisfrom the relationships between those indices and general research. In addition, the different SIR indicators are found to be strongly correlated.

Figure 1 Pearson and Spearman correlation coefficients between the number of coordinated projects funded in the analysed timeframe and the Scimago Institutions Ranking positions in 2017. Notice that the negative associations result from the fact that the ranking value introduced is the ranking position. Consequently, the relationship between the number of projects and a ranking variable should be interpreted as follows: a higher position in the ranking (and therefore a lower value) indicates a higher number of projects obtained.
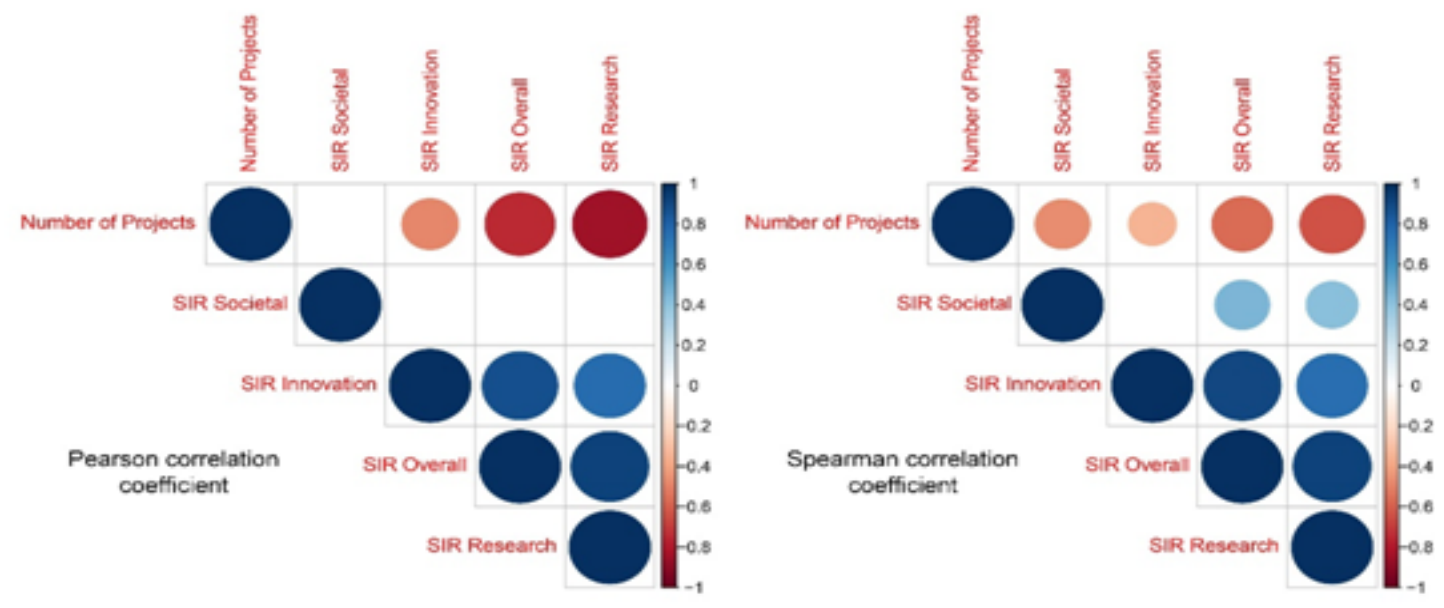

As regards the third research question, i.e., to determine if interdisciplinarity and multidisciplinarity in Spain respond to geographic patterns, we have conducted different analyses. The first analysis consisted in the georeferentiation of the net-work of institutions, that is, in locating each institution (node) in accordance with its latitude and longitude. Remember that there exists a link between two institutions if they have collaborated in a coordinated project in the time frame considered. The weight of each link indicates the number of shared projects by both institutions (See Fig. 3). 
Figure 3 Visualisation of the weighted network of the relationships between research institutions in Spain derived from the coordinated projects from the Spanish Ministry of Science and Innovation that they shared in the 2013- 2018 timeframe. Nodes (institutions) have been positioned in accordance with their geolocation. The Spanish National Research Council (CSIC) has been split into research centres to show a lower bias in the spatial distribution.

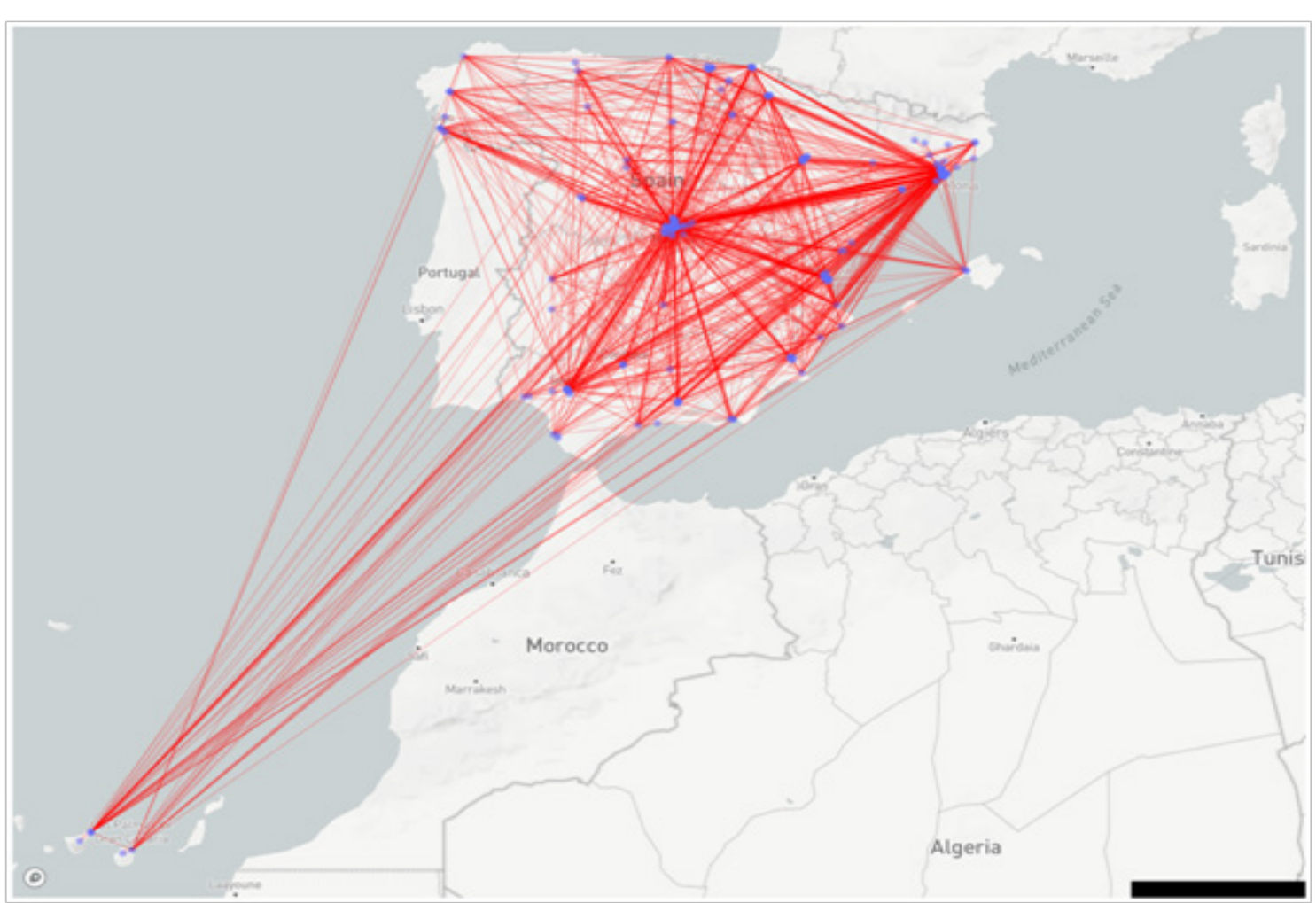

The analysis of the map in Fig. 3. suggests different issues of interest. The first of them is that research does not seem to be evenly distributed from a geographical perspective, existing different poles of attraction. To confirm these intuitions, additional analyses were carried out.
Firstly, we obtained the distribution of coordi-nated projects by autonomous community (Fig. 4), which served to illustrate that there exists a high concentration of multidisciplinary research in the communities of Madrid, Catalonia, Andalusia and Valencia.
Figure 4 Distribution by autonomous community of the coordinated projects granted in the Excellence and Challenge project calls of the State R\&D\&I Program of the Spanish Ministry of Science and Innovation (2013-2018).

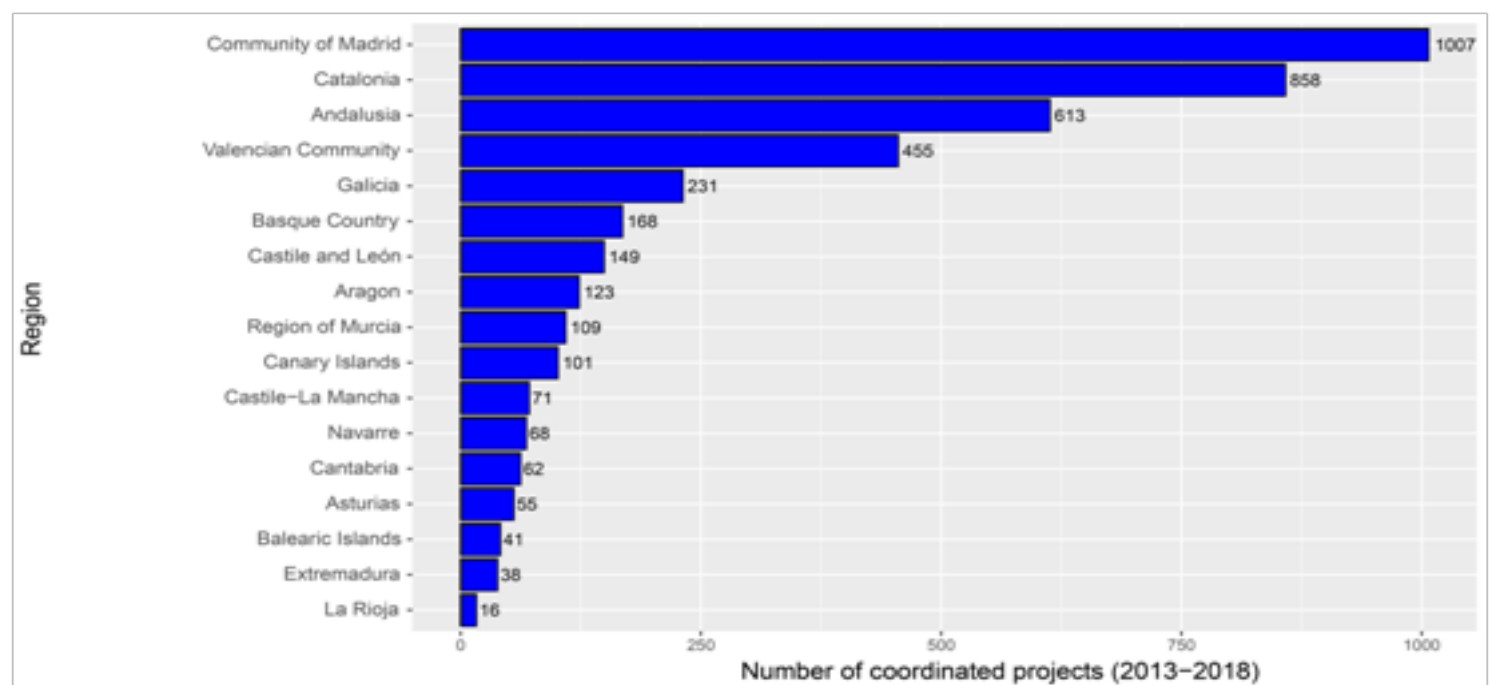


The formal assessment of inequality in the above distribution was conducted using the Lorenz curve and the Gini coefficient (see Fig. 5). We obtained a Gini value greater than 0.5 , which indicates that coordinated projects are unequally distributed among the different autonomous communities, thus confirming the concentration of research activity in general, and of multidisciplinary research in particular, in certain geographical poles.

Figure 5 Lorenz curve and Gini coefficient of the distribution of coordinated projects granted in the Excellence and Challenge project calls of the State R\&D\&I Program of the Spanish Ministry of Science and Innovation (2013-2018) per autonomous community

\section{Lorenz curve}

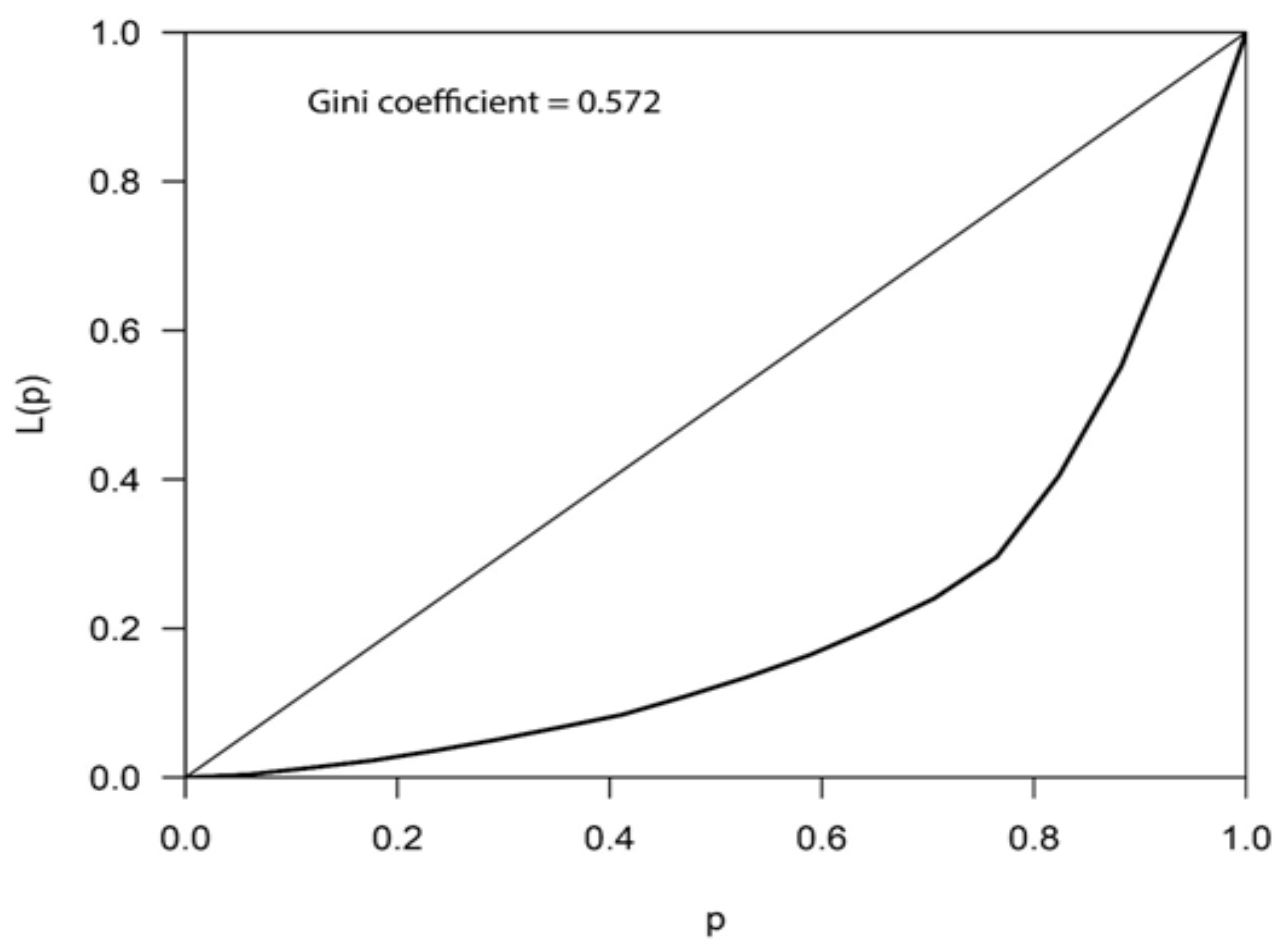

\subsection{Analysis of the Network of ANEP thematic areas}

In this second block, the focus is on the role that each of the scientific disciplines (under the ANEP classification) plays in multidisciplinary research in Spain in accordance with the coordinated projects. Fig. 6 presents the distribution of the number of coordinated projects by ANEP thematic area in the 2013-2018 time-frame. It shows the importance of Engineering and Physical Sciences in capturing multidisciplinary funding (acronym descriptions of the scientific fields can be found in Table 2). The four scientific areas with the most projects -excluding universities and institutes without direct field assignment- are Industrial Production and Civil Engineering, Information and Communication Technologies (TIC in Spanish), Environmental Sciences and Technologies, and Physics. 
Figure 6 Number of coordinated projects by ANEP scientific area in the Excellence and Challenge project calls of the State R\&D\&I Program of the Spanish Ministry of Science and Innovation (20132018).

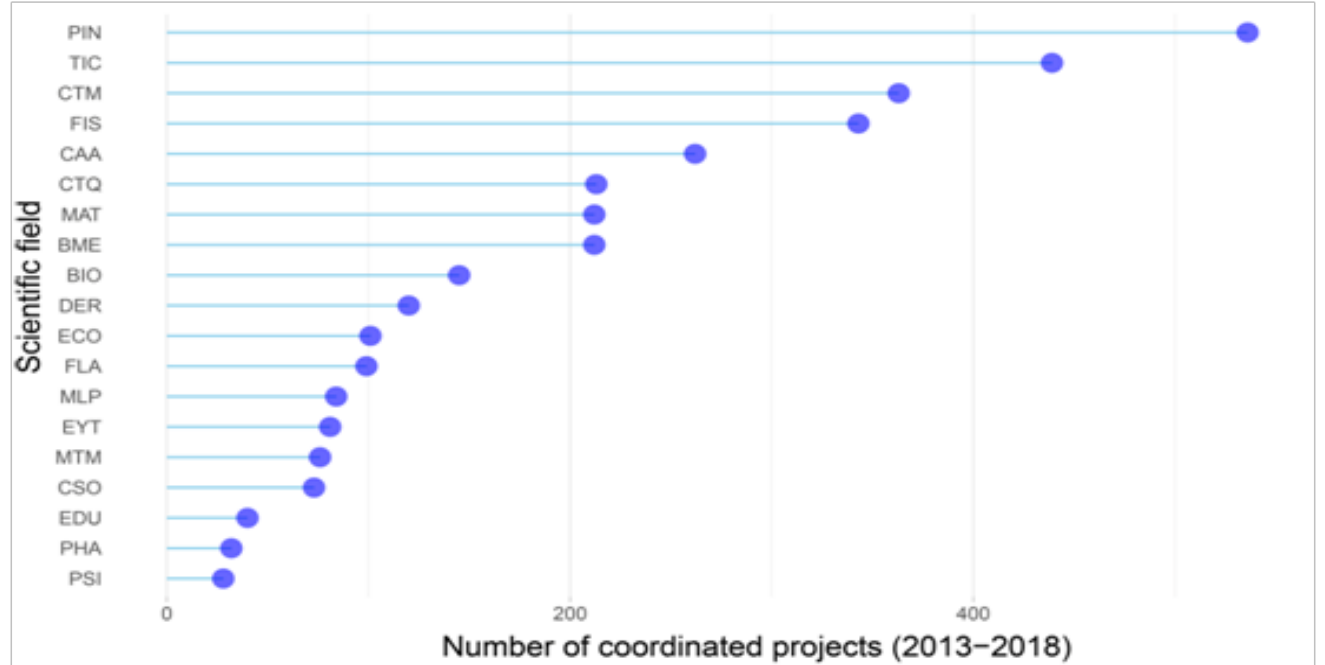

As pointed in the data and problem formalisation section, the relationship between the coordinated projects and the ANEP thematic areas was also explored by means of a network approach. To that end, each institution (requesting centre) was associated with a given thematic area in accordance with its name. In this second network, the ANEP thematic areas constitute the nodes, and a link exists between two areas if there is a coordinated project that connects two centres associated with those thematic areas; the links are weighted, indicating the weight the number of projects that connect each pair of nodes. In principle, the network contains selfloops, which represent coordinated projects in which both centres belong to or are associated with the same scientific field. Figure 7 shows on the left the network with self-loops, thus faithfully representing the structure of collaboration characteristic of coordinated projects. On the right, the network without self-loops is presented; since the self-loops have been removed, it is more focused on multidisciplinary relationships between scientific disciplines. Please note that the centres that are not clearly associated with a thematic area have been included in a generic category (gen).
In both cases -with and without self-loops- the community structure of the network of thematic areas was evaluated. For the sake of simplicity, we relied again on Louvain's algorithm (best modularity obtained after 100 iterations of the algorithm).

Including self-loops, seven communities were found, the tentative interpretation of which can be summarised as follows: (i) the purple community comprises the Social and Legal Sciences; (ii) the blue community is related to Civil Engineering, Physics and Transport; (iii) the light green community is the community of the Life Sciences: Biomedicine, Biotechnology and Environmental and Agricultural Sciences; (iv) the brown community is constituted by the Information and Com-munication Technologies (TIC) and Mathematics; the orange community includes Chemistry and Materials Science; and finally, the dark green community (Economics) and the red community (Law) constitute communities with only one node. These results evince that scientific collaboration processes are governed by the affinity between areas in a very relevant way. 
Figure $\quad 7$ Network of

thematic areas. The

different communities

identified with the Louvain

algorithm are coloured

differently. On the left, self-

loops are taken into

account. On

the right, self-loops have

been removed prior to

community detection.

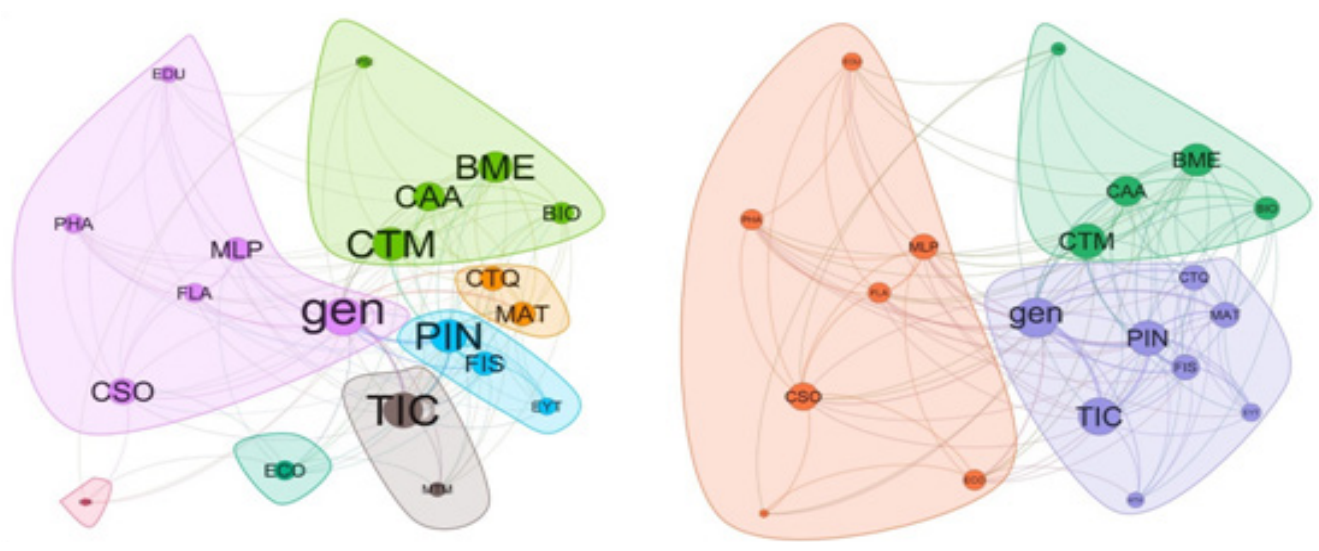

On the right side of Fig. 7., i.e., after eliminating selfloops to analyse the sheer multidisciplinary relationships in more detail, the communities detected by the algorithm are larger than in the previous case. Economics and Law are grouped together with the rest of Social Sciences (orange community), the green community of Life Sciences is not altered (green community) and an additional community (violet community) groups different Engineerings, Physics, Mathematics and Chemistry.

On this last partition -the one without self-loopswe conducted a role detection analysis too, to determine if there are disciplines or thematic areas that are decisive in interdisciplinary scientific projects. The results of this analysis are shown in Fig. 8. Those results reveal that no discipline acts as a hub within the thematic areas network, as the roles of the different scientific disciplines present a marked homogeneity. The only exception is that of Education, which acts as a field with a relevant level of participation among the different communities (role R3); the rest of the disciplines are all peripheral nodes of the communities to which they belong. There is, of course, a certain level of variability in the number of projects reflected on the vertical axis, and in the participation coefficient of each discipline on the horizontal axis, but there are no major structural differences between the roles that the different disciplines play in the network as a whole.
Figure 8 Network of

thematic areas. The

different communities

identified with the Louvain algorithm are coloured differently. On the left, selfloops are taken into account. On the right, self-loops have been removed prior to community detection.

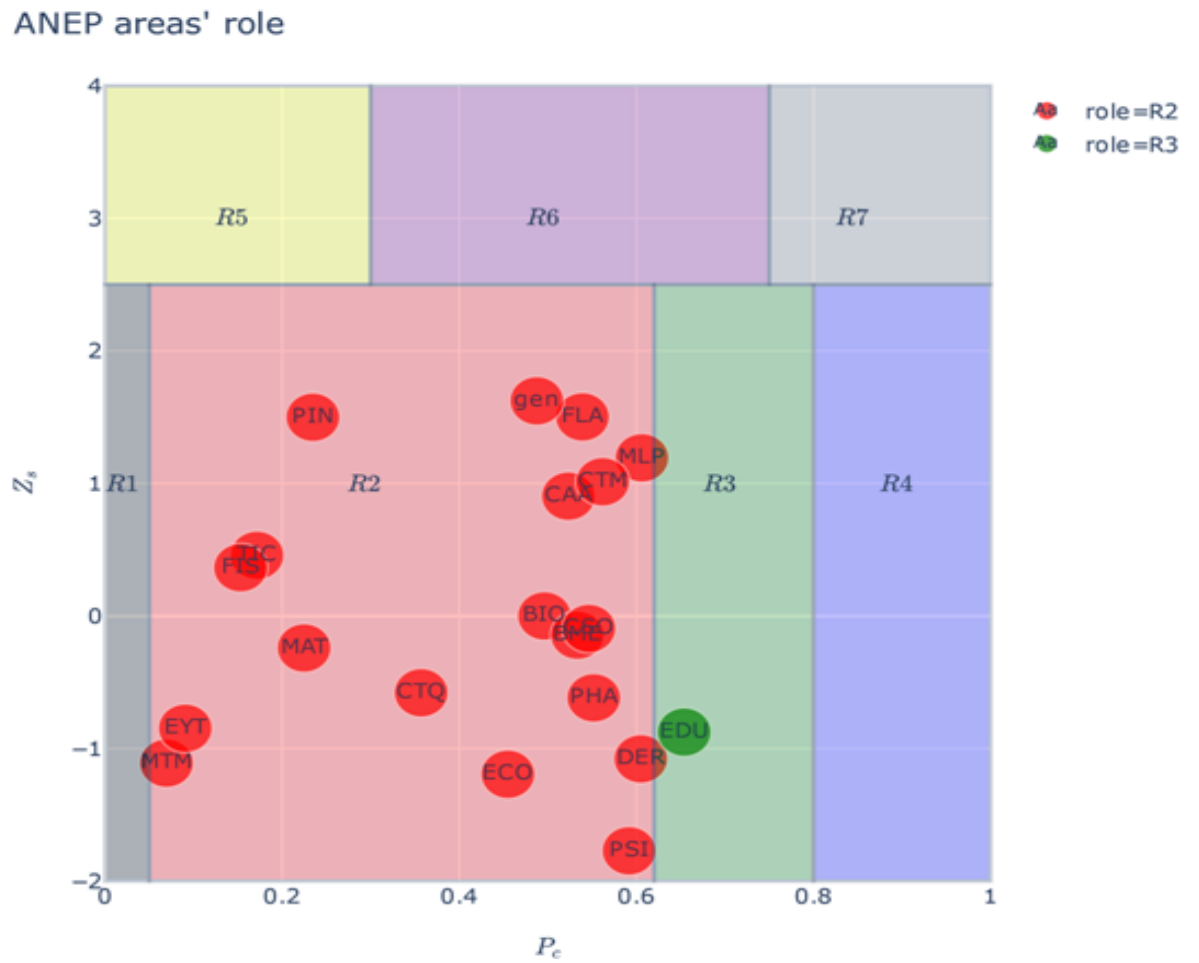


To conclude the analysis of the network of the ANEP thematic areas, and so as to obtain a more complete picture, some of the most relevant node centrality measures of the network have been obtained, namely degree -the number of links of a node to other nodes in the network-, betweenness -the degree of intermediation of a node between all nodes in the network- and Page Rank -a node centrality measure according to which the centrality that a node derives from its neighbours is proportional to their centrality and diluted when shared among many nodes- (Barabási 2016). Table 2 presents the details of the results obtained for the different scientific areas. Please note that the ANEP areas have been sorted in descending order of degree.
Table 2 List of the ANEP thematic areas arranged by descending order of their degree value. Their values of betweenness and Page Rank are also provided.

\begin{tabular}{|c|c|c|c|c|}
\hline & Description & Weighted Degree & Betweenness & Page Rank \\
\hline gen & $\begin{array}{l}\text { Universities and } \\
\text { institutes not specified }\end{array}$ & 774 & 12.413 & 0.0731 \\
\hline PIN & $\begin{array}{l}\text { Industrial production, } \\
\text { civil engineering }\end{array}$ & 582 & 5.613 & 0.0649 \\
\hline TIC & $\begin{array}{l}\text { Information and commu- } \\
\text { nications technologies }\end{array}$ & 358 & 9.319 & 0.0691 \\
\hline FIS & Physics & 337 & 2.403 & 0.0504 \\
\hline CTM & $\begin{array}{l}\text { Environmental sciences } \\
\text { and technologies }\end{array}$ & 240 & 9.993 & 0.0659 \\
\hline MAT & $\begin{array}{l}\text { Materials science and } \\
\text { technology }\end{array}$ & 235 & 1.759 & 0.0501 \\
\hline CTQ & $\begin{array}{l}\text { Chemical sciences and } \\
\text { technologies }\end{array}$ & 191 & 1.934 & 0.0503 \\
\hline CAA & $\begin{array}{l}\text { Agricultural and } \\
\text { agrifood sciences }\end{array}$ & 168 & 5.445 & 0.0581 \\
\hline BME & Biomedicine & 134 & 5.329 & 0.0615 \\
\hline MLP & $\begin{array}{l}\text { Mind, language and } \\
\text { thinking }\end{array}$ & 111 & 2.607 & 0.0505 \\
\hline EYT & Energy and transport & 106 & 0.504 & 0.0392 \\
\hline $\mathrm{BIO}$ & $\begin{array}{l}\text { Biosciences and } \\
\text { biotechnology }\end{array}$ & 103 & 0.913 & 0.0466 \\
\hline FLA & $\begin{array}{l}\text { Culture, philology, } \\
\text { literature and art }\end{array}$ & 97 & 1.094 & 0.0430 \\
\hline $\mathrm{CSO}$ & Social Sciences & 58 & 5.517 & 0.0553 \\
\hline MTM & Mathematical Sciences & 58 & 0.386 & 0.0358 \\
\hline $\mathrm{ECO}$ & Economics & 55 & 2.709 & 0.0438 \\
\hline PHA & $\begin{array}{l}\text { Studies of the past, } \\
\text { history and archeology }\end{array}$ & 35 & 1.346 & 0.0431 \\
\hline EDU & Education sciences & 29 & 1.096 & 0.0400 \\
\hline DER & Law & 20 & 0.426 & 0.0258 \\
\hline PSI & Psychology & 13 & 1.192 & 0.0332 \\
\hline
\end{tabular}




\section{Conclusions and future research}

This contribution constitutes a comprehensive analysis of multidisciplinarity within the Spanish scientific community. We have identified the institutions that lead multidisciplinary research in Spain, such as CSIC and technical universities, and we have determined the role that they play in the whole network of institutions, which, as could be expected, is either predominantly connective or centred in the community to which the institution belongs. Moreover, we have assessed if the position of the institutions in accordance with the different indicators of the Scimago Institutions Ranking partially explains a greater or lower level of multi-disciplinarity. In this regard, we found a robust association between the number of coordinated projects an institution is awarded and a high-ranking position in both the SIR Research index and the SIR Overall index. Eventually, we explored the geographic patterns of multidisciplinary research in Spain and found that coordinated projects are unequally distributed among autonomous communities, existing geographical poles of attraction: Madrid, Catalonia, Andalusia and Valencia.

As for the analysis of the ANEP thematic areas, we identified the scientific areas with the most coordinated projects, namely Industrial Production and Civil Engineering, Information and Communication Technologies, Environmental Sciences and Physics. In addition, the network of the ANEP thematic areas -both with and without self-loops- was found to have a clear modular structure that reveals how scientific collaboration is markedly governed by the affinity between areas. Ultimately, the role detection analysis conducted on this network suggests that all disciplines have a similar role in the network, being none of them a hub that is pivotal for interdisciplinary research.

To conclude, future research lines worth exploring would be other classifications per thematic area and the assessment of the relationship between the funding obtained by multidisciplinary projects and the team productivity.

\section{Acknowledgments}

The authors acknowledge financial support from the Spanish Ministry of Science, Innovation and Universities (excellence networks HAR2017-90883-REDC and RED2018-102518-T, as well as FEDER (Spain/EU) grant PGC2018-098186-B-I00 (BASIC)); and from the Junta de Castilla y León - Consejería de Educación through BDNS 425389, the predoctoral grants awarded to Virginia Ahedo and Silvia Díaz-de la Fuente (supported by the European Social Fund) and the financial aid awarded to Silvia Díaz-de la Fuente, destined to employ research assistants by Public Universities of Castilla y León, being aimed at young people registered in the National System of Youth Guarantee and co-supported by the European Social Fund and the Youth Employment Initiative. We also acknowledge Santander Supercomputación support group at the University of Cantabria who provided access to the supercomputer Altamira Supercomputer at the Institute of Physics of Cantabria (IFCA-CSIC), member of the Spanish Supercomputing Network, for performing simulations/analyses.

\section{References}

BARABÁSI, A. L. (2016). Network Science. Cambridge University Press.

BENSON, M. H., LIPPITT, C. D., MORRISON, R., COSENS, B., BOLL, J., CHAFFIN, B. C., FREMIER, A. K., HEINSE, R., KAUNECKIS, D., LINK, T. E., SCRUGGS, C. E., STONE, M. \& VALENTIN, V. (2016). «Five ways to support interdisciplinary work before tenure». Journal of Environmental Studies and Sciences, 6(2), pp. 260-267, doi:10.1007/s13412-0150326-9.

BLONDEL, V. D., GUILLAUME, J.-L., LAMBIOTTE, R. \& LEFEBVRE, E. (2008). «Fast unfolding of communities in large networks». Journal of Statistical Mechanics: Theory and Experiment, 2008(10), p. P10008, doi:10.1088/1742-5468/2008/10/P10008.

BROWN, J., MURRAY, D., FURLONG, K., COCO, E. \& DABLANDER, F. (2021). «A breeding pool of ideas: Analyzing interdisciplinary collaborations at the Complex Systems Summer School». PLOS ONE, 16(2), p. e0246260, doi:10.1371/journal.pone.0246260.

CARO, J., DÍAZ-DE LA FUENTE, S., AHEDO, V., ZURRO, D., MADELLA, M., GALÁN, J. ., IZQUIERDO, L. ., SANTOS, J. I. \& DEL OLMO, R. (2020a). «La necesidad de la colaboración científica». In: Caro, J., Díaz-de la Fuente, S., Ahedo, V., Zurro, D., Madella, M., Galán, J. ., Izquierdo, L. ., Santos, J. I., \& del Olmo, R. (eds.) Terra Incognita: Libro blanco sobre transdisciplinariedad y nuevas formas de investigación en el Sistema Español de Ciencia y Tecnología. Burgos: PressBooks, pp. 9-14.

CARO, J., DÍAZ-DE LA FUENTE, S., AHEDO, V., ZURRO, D., MADELLA, M., GALÁN, J. M., IZQUIERDO, L. R., SANTOS, J. I. \& DEL OLMO, R. (2020b). «Multidisciplinariedad, interdisciplinariedad, transdisciplinariedad». In: Caro, J., Díaz-de la Fuente, S., Ahedo, V., Zurro, D., Madella, M., Galán, J. M., Izquierdo, L. R., Santos, J. I., \& del Olmo, R. (eds.) Terra Incognita: Libro blanco sobre transdisciplinariedad y nuevas formas de investigación en el Sistema Español de Ciencia y Tecnología. Burgos: PressBooks, pp. 15-20. 
DÍAZ-DE LA FUENTE, S., AHEDO, V., CARO, J., PEREDA, M., SANTOS, J. I. \& GALÁN, J. M. (2020). "Análisis de la multidisciplinariedad de la investigación en España mediante la red de proyectos de $\mathrm{I}+\mathrm{D}+\mathrm{I}$ coordinados». In: Caro, J., Díaz-de la Fuente, S., Ahedo, V., Zurro, D., Madella, M., Galán, J. M., Izquierdo, L. R., Santos, J. I., \& del Olmo, R. (eds.) Terra Incognita: Libro blanco sobre transdisciplinariedad y nuevas formas de investigación en el Sistema Español de Ciencia y Tecnología. Burgos: PressBooks, pp. 29-44.

DOBLARÉ CASTELLANO, M. \& ALARCÓN ÁLVAREZ, E. (2008). Retos y oportunidades de la investigación transdisciplinar. Madrid.

FAIR, H. (2010). «Hacia la transdisciplinariedad». ConSciencias Sociales 2, 2(1), pp. 19-26.

GUIMERÀ, R. \& AMARAL, L.A. N. (2005a). «Cartography of complex networks: modules and universal roles». Journal of Statistical Mechanics: Theory and Experiment, 2005(02), p. P02001, doi:10.1088/1742-5468/2005/02/ P02001.

GUIMERÀ, R. \& AMARAL, L. A. N. (2005b). «Functional cartography of complex metabolic networks». Nature, 433(7028), pp. 895-900, doi:10.1038/nature03288.

LANCICHINETTI, A. \& FORTUNATO, S. (2009). «Community detection algorithms: A comparative analysis». Physical Review E - Statistical, Nonlinear, and Soft Matter Physics, 80(5), pp. 1-12, doi:10.1103/ PhysRevE.80.056117.

LAWRENCE, R. J. \& DESPRÉS, C. (2004). «Futures of Transdisciplinarity». Futures, 36(4), pp. 397-405, doi:10.1016/j.futures.2003.10.005.

LAZER, D. M. J., PENTLAND, A., WATTS, D. J., ARAL, S., ATHEY, S., CONTRACTOR, N., FREELON, D., GONZALEZ-BAILON, S., KING, G., MARGETTS, H., NELSON, A., SALGANIK, M. J., STROHMAIER, M., VESPIGNANI, A. \& WAGNER, C. (2020). «Computational social science: Obstacles and opportunities». Science, 369(6507), pp. 1060-1062, doi:10.1126/science.aaz8170.
LEONE SCIABOLAZZA, V., VACCA, R., KENNELLY OKRAKU, T. \& MCCARTY, C. (2017). «Detecting and analyzing research communities in longitudinal scientific networks». PLOS ONE, 12(8), p. e0182516, doi:10.1371/journal.pone.0182516.

MOBJÖRK, M. (2010). «Consulting versus participatory transdisciplinarity: A refined classification of transdisciplinary research». Futures, 42(8), pp. 866873, doi:10.1016/j.futures.2010.03.003.

NEWMAN, M. E. J. \& GIRVAN, M. (2004). «Finding and evaluating community structure in networks». Physical Review E, 69(2), p. 026113, doi:10.1103/ PhysRevE.69.026113.

RAMADIER, T. (2004). «Transdisciplinarity and its challenges: the case of urban studies». Futures, 36(4), pp. 423-439, doi:10.1016/j.futures.2003.10.009.

VARGAS QUESADA, B., BUSTOS-GONZÁLEZ, A. \& DE MOYA ANEGÓN, F. (2017). «Scimago Institutions Rankings: The Most Comprehensive Ranking Approach to the World of Research Institutions». In: Research Analytics. New York, NY: Auerbach Publications, pp. 147-160.

XIE, Z., LI, M., LI, J., DUAN, X. \& OUYANG, Z. (2018). «Feature analysis of multidisciplinary scientific collaboration patterns based on PNAS». EPJ Data Science, 7(1), p. 5, doi:10.1140/epjds/s13688-0180134-z.

ZUO, Z. \& ZHAO, K. (2018). «The more multidisciplinary the better? - The prevalence and interdisciplinarity of research collaborations in multidisciplinary institutions». Journal of Informetrics, 12(3), pp. 736756, doi:10.1016/j.joi.2018.06.006. 